\begin{tabular}{c} 
Volume and Issues Obtainable at Center for Sustainability Research and Consultancy \\
Journal of Business and Social Review in Emerging Economies \\
ISSN: 2519-089X \& ISSN (E): 2519-0326 \\
Volume 7: Issue 2 June 2021 \\
CSRC \\
Journal homepage: $\underline{\text { www.publishing.globalcsrc.org/jbsee }}$ \\
\hline
\end{tabular}

\title{
Key Assessment Indicators of Infrastructure for the Sustainability of Economic Development: An Empirical Investigation of Pakistan
}

*Hina Ali, Department of Economics, The Women University Multan, Pakistan Nazia Nasir, Department of Economics, The Women University Multan, Pakistan Tahira Qasim Bano, Department of Statistics, The Women University Multan, Pakistan Aiman Javaid, Department of Economics, The Women University Multan, Pakistan

*Corresponding author's email: hinaali@wum.edu.pk

ARTICLE DETAILS

History

Revised format: May 2021

Available Online: Jun 2021

\section{Keywords}

Gross Domestic Product,

Gross Fixed Capital

Formation, Health

Expenditures, Total

Generation of Electricity,

Labor Force.

JEL Classification

E10, G31, I15, L94, J08,

I28

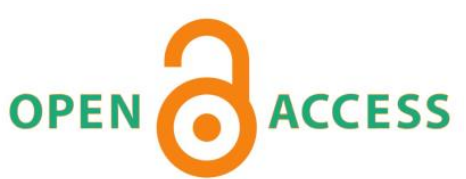

\section{ABSTRACT}

Purpose: This study addresses the linkage between the gross domestic product and infrastructure in Pakistan. The time frame taken for this study is from 1977-2019. The information utilized in this study is taken from reliable sources; World Bank.

Methodology: ARDL method is utilized in this study with the assistance of E-VIEWS 10 programming. To consider the effect of infrastructure on GDP; the factors are utilized, for example, gross fixed capital formation, health expenditures, total generation age of power, life expectancy, and government expenditure on education.

Findings: The consequences of this study show that the gross fixed capital formation, wellbeing consumption, and workforce have a positive connection to GDP. Then again, the total generation of electricity and government expenditures on schooling adversely affect the economy of Pakistan. The infrastructure is one of the principals and fundamental variables for the improvement of the economy of Pakistan. The helpless state of infrastructure in Pakistan is probably the greatest deterrent in the advancement of the country. The public authority should zero in on the upgrading of the approaches in regards to the infrastructure area.

Implication: This study witnesses a positive link with the gross domestic product of Pakistan, this is the reason the government of Pakistan should work on the development of the labor force. For the development of the labor force, the government should organize training sessions, workshops, institutions for technical and vocational education, and many other projects.

(C) 2021 The authors, under a Creative Commons AttributionNonCommercial 4.0

Recommended citation: Ali, H., Nasir, N., Bano, T. Q. and Javaid, A. (2021). Key Assessment Indicators of Infrastructure for the Sustainability of Economic Development: An Empirical Investigation of Pakistan. Journal of Business and Social Review in Emerging Economies, 7 (2), 
$389-401$.

\section{Introduction}

Infrastructure is one of the main elements for sustained economic growth. Infrastructure can be characterized as the arrangement of interconnected primary basics that convey the system auxiliary a whole gathering of advancement. It tends to be utilized as a compelling apparatus to pass judgment on the economic advancement of a country because cutting-edge and upgraded infrastructural addresses the economic growth or development of a country. Developed infrastructure refers to roads, telecommunication, educational institutions, hospitals, water and sanitation, power generation, etc. Poor or less developed infrastructure is perhaps the greatest hurdle in the way of economic development especially for developing countries like Pakistan. In this paper association between gross domestic product and infrastructure is discussed, while using other variables like gross fixed capital formation, health expenditures, total generation of electricity, the labor force, and government expenditures on education. These variables are used as a proxy of infrastructure.

The gross domestic product pace of a country stands for its escalation stage. The advanced gross domestic product demonstrates that the country is performing sound and the financial circumstances of the country are steady and helpful. GDP speed illustrates variations in the case of Pakistan. Because many interior and exterior features affect this speed; such as political wavering, war and terror conditions, climatic settings, the occurrence of migrants, deflation of currency, foreign debt, unfavorable balance of payment, inappropriate policies related to trade, and many others.

Spending on the improvement of land, plant, machinery, the construction of new roads, railways, and industrial buildings is known as gross fixed capital formation. In other words, the net addition to the existing capital stock is gross fixed capital formation. Gross fixed capital formation helps to improve the infrastructure of the country through the construction of new roads, plants, and more. Installation of new plants and equipment increases the productivity of the economy. The enhanced productive process of the economy attracts new investors from other developed countries. In this study, a positive relationship is found between gross domestic product and gross fixed capital formation of Pakistan. This shows that the installation of new machinery and plants in the country will increase the gross domestic product of Pakistan.

Health expenditures are the main component of a person's budget constraint. The spending on the health infrastructure and the improvement of the health sector by the government of a country is also known as health expenditure. The improvement of the health sector means the provision of better facilities to the public, the subsidies given to the common people in the form of cheap medicines, the construction of new hospitals, and many other benefits by the government to the public. The outcomes of the analysis of this study describe that the association between gross domestic product and health expenditures of Pakistan is direct.

Electricity is considered the lifeline of any economy and the most important tool for the working procedure of a country. For any government, the most important and as well as difficult part is to provide nonstop electricity to the industries and the public. As the population growth rate is increasing day by day as compared to the sources of electricity generation. Therefore, the electricity demand increased a lot but not the supply of electricity. The greater difference between demand and supply of electricity is the main cause of breakdowns of electricity which in turn cause a great loss to the industrial and manufacturing sector. The link between the gross domestic product and the total generation of electricity in the case of Pakistan is negative in this study.

The labor force of a country is an essential part of the economy of that country. The skilled, 
developed and educated labor force of a country represents the enhanced and improved economic growth of that country. In this study, a positive relationship exists between gross domestic product and the labor force. It means the higher the level of the labor force the higher will be the growth of the gross domestic product.

Education performs an important and essential role in the formation of human capital. It also performs the character of leadership in society. The job of educational institutions is to help people to grow mentally, psychologically, socially, and spiritually. It develops the economic, social, political, and cultural life of the nation. A very close and strong link exists between education and development. In this study the association between the gross domestic product of Pakistan and government expenditures on education is negative. When the government of Pakistan spends more on education, then because of this spending the gross domestic product of Pakistan falls. The reason behind this action is poor management, corruption, political instability, lack of public interest, and low quality of statistical data.

\section{Literature Review}

Bougheas, Demetriades, and Morgenroth (2003) found an important positive link between infrastructure and degree of specialization. The consequences presented that economic progress showed different cycles by improving the infrastructure sector. Such as; economic progress was raised in the starting then it reached its boom period then it started to decline as the new infrastructure was planted in the economy. It had proved that a greater supply of infrastructure than demand created so many problems in the country.

Yilmaz, Haynes, and Dinc (2002) studied the significance of the telecom sector in the development of the US economy. The expansion of the telecom sector became the reason for enhanced economic growth because it increased the productive capacity of the economy. Canning and Pedroni (2004) investigated the long-run association between infrastructure and economic progress. The findings showed that the countries which improved their infrastructure with the passage of time witnessed great success, while those countries which did not consider infrastructural development as a tool of progress were facing hurdles in the way of progress.

Mahmood, Hafeez-ur-Rehman, and Rauf (2008) found out that for the comprehensive economic progress of a country, the economic policies arranged by the policymakers and economists played a vibrant role. More the precise the police or more the policies suitable for the economic environments of the state, the more the economy grows, and the results exposed the rise in gross domestic product. The economy succeeded only when the execution of the right economic policies along with the upgraded infrastructure facilities provide a sound base to the investors, both local and international. The above-mentioned condition for economic growth relied on the country's internal law and order situation, administration, and other internal and external shocks.

Estache et al. (2009) indicated that the infrastructure installed through the help of international donations produced Dutch Disease effects, but the kind of investment described those effects; negative or positive. The impacts of economic development helped to weaken the negative effects. World Economic Forum (2010) defined the various stages of factors that determined the growth of the countries based on their detailed phases of advancement. Based on those factors Pakistan drop in the first stage of expansion. Consequently; infrastructure, education, water supply, energy, and basic health facilities were the most important factors for the expansion of Pakistan.

Dissou and Didic (2011) stated that the crowding out consequences of public infrastructure showed a delicate nature towards the techniques of sponsoring selected by the government. The outcomes described that sponsoring in the sector of infrastructure by the government encouraged the private sector to invest in infrastructure, which ultimately helped to achieve continuous economic 
growth. To the crowd in private investment, the public-private partnership and sub-contracting between public and private sectors helped the government to develop the infrastructure of the country.

Afzal (2012) studied the impact of the energy crisis on the textile sector of Pakistan. Energy or electricity worked as blood for all the sectors of the economy, especially for the industrial sector. Less production of energy than its demand created a great shortage in the country. The output level of the textile sector decreased due to the supply-demand difference because of the operating time contracted in the industries due to the shortage of electricity. The low level of output by the industries increased the production costs for the factories. As the public sector failed to provide good facilities of infrastructure to the industries. As the alternative that industries produced energy by using private resources but the cost of doing that was high and cause loss to the industries.

Rao and Srinivasu (2013) found out the association between economic development, infrastructure, and poverty. The results displayed that there was a direct link between infrastructure and economic development and a direct link between infrastructure and poverty. The level of poverty in the country declined with the help of developed infrastructure and as a result, the low poverty level forced the economy to move toward advancement. Aoyagi Sawada and Shoji (2014).due to poor irrigation infrastructure reduced the $45 \%$ working labor engaged in the agricultural sector. The lack of access to agricultural infrastructure increased poverty at a lower level. The ultimate result of poor infrastructure appeared as a less developed agricultural sector, which in turn yield a low level of output.

Tanveer and Manan (2016) examined the impact of infrastructure on the economic growth of Pakistan and stated that for economic development especially for a less developed country such as Pakistan advanced infrastructure played an important role in that development. Investment in the field of infrastructure became the reason for increased job opportunities, improved production systems through advanced technology, and above all these developments that investment boosted the economic actions.

Boadi et al. (2017). stated that to fill up the gap of infrastructure in the country, the private capital worked as an influential factor for the advancement of infrastructure. The investment by the private sector in the field of infrastructure is done by directly purchasing public originalities and mutual possession contracts or in the form of Build - Own - Operate and Transfer (BOOT) plans. Those plans helped the governments to increase the funds to invest in the infrastructure sector of the country.

Samia (2018) wrote a report on the state of the health sector in Pakistan and described the reputation of the condition of health infrastructure concerning the continuous mounting population. The delivery of medical facilities is based on the state and accessibility of elementary health infrastructure or the combination of health institutions and health staff. The number of sickrooms, basic health units (BHUs), number of beds in hospitals, dispensaries, health personnel, etc represented the many indicators of health infrastructure.

Rygzynov and Tsydypov (2019) examined the consequences of the delivery of infrastructure for the long run on the per capita for a panel data of countries. The statistics showed that the infrastructure put mostly long-run effects on the economic performance of the country. However, infrastructure put different impacts in different countries.

Model Specification, Data, and Methodology Model Specification

In this mold, the association between GDP and other variables like GFCF, HE, TGE, LF, and 
GEE will be predicted. The variables which are used in this manuscript are selected very consciously from the studies of other researchers. Under this caption, the dependent and independent variables of this manuscript are described. The dependent variable of this article is Gross Domestic Product while the independent variables are Gross Fixed Capital Formation, Health Expenditure, Total Generation of Electricity, Labor Force, and Government Expenditures on Education.

Table 1: Description of Variables

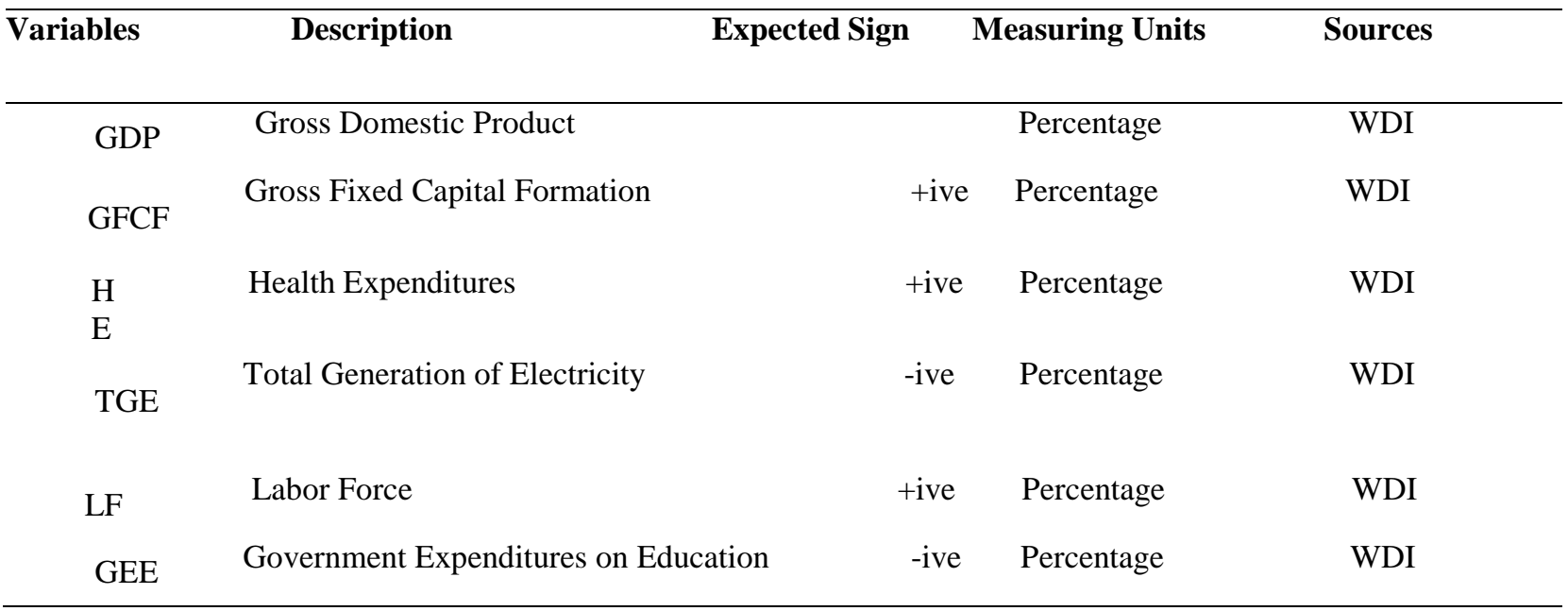

\section{Source: The data is taken from World Development Indicator}

The above table represents the capricious chosen for this paper. Further, the measuring components for these capricious are also exposed and the foundation from which the records of these variables are composed is also mentioned. While the column of Expected Sign represents the relationship between the dependent variable and the independent variables. The detailed definition of the above-mentioned variables is written below:

\section{Gross Domestic Product}

GDP is the acronym of gross domestic product. Gross domestic product is defined as the increase in the per capita income of a country over a period. The per capita income of a country is obtained by dividing its total population by its total national income. This increase in per capita income represents that the living standard of the people of the country is improving and the economy is developing. Different countries have different gross domestic product rates, which describes their rate or level of growth and development.

\section{Gross Fixed Capital Formation}

Gross fixed capital formation states to net accumulation in the existing assets stock of the economy. For example, installation of new equipment, construction of new roads, etc.

\section{Health Expenditures}

Overall spending on health care calculates the absolute utilization of health merchandise and services in addition to capital investment in health care infrastructure. Health expenditures are generally described as actions executed either by organizations or persons through the appliance of the health check, paramedical or nursing comprehension, and expertise, the chief principle of which is to encourage, restore or sustain health.

\section{Total Generation of Energy}

Electricity generation is the process of generating electric power from sources of primary energy. 
For electric utilities in the electric power industry, it is the first stage in the delivery of electricity to end-users, the other stages being transmission, distribution, energy storage, and recovery, using pumped-storage methods.

\section{Labor Force}

The labor force, also called the workforce, is the population of able-bodied, willing people who are currently employed or looking for work. In other words, it's a representation of the labor pool of a certain country or segment of the economy.

\section{Government Expenditures on Education}

Government expenditure on education includes expenditure funded by transfers from international sources to the government. The general government usually refers to local, regional, and central governments.

\section{Results and Discussions}

The results of the study are measured by using the ARDL method with the assistance of EVIEWS 10 programming Descriptive Statistics, Correlation, and Analysis. The results of Descriptive Statistics are given in table 4

Table 4: Descriptive Statistics

\begin{tabular}{|c|c|c|c|c|c|c|}
\hline & GDP & GFCF & HE & TGE & $\mathbf{L F}$ & GEE \\
\hline Mean & 4.9137 & 16.2019 & 0.7034 & 57.1016 & S50940668 & 2.4329 \\
\hline Medium & 4.8463 & 16.8371 & 0.7300 & 62.6726 & 53655064 & 2.4918 \\
\hline Maximum & 10.2157 & 19.2354 & 1.2500 & 71.8260 & 69957925 & 3.0223 \\
\hline Minimum & 1.0143 & 12.5206 & 0.2300 & 37.9959 & 31130954 & 1.8378 \\
\hline Std. Dev & 2.0448 & 1.6622 & 0.2141 & 10.4251 & 11801104 & 0.3036 \\
\hline Skewness & 0.2503 & -0.4922 & 0.0230 & -0.4368 & -0.1966 & -0.0518 \\
\hline Kurtosis & 2.7581 & 2.2946 & 3.4432 & 1.6888 & 1.8873 & 2.1715 \\
\hline Jarque - Bera & 0.5538 & 2.6276 & 0.3558 & 4.4472 & 2.4952 & 1.2488 \\
\hline Probability & 0.7581 & 0.2687 & 0.8370 & 0.1082 & 0.4952 & 0.5355 \\
\hline Sum & 211.2898 & 696.6824 & 30.2500 & 2455.372 & 2.1900 & 104.6167 \\
\hline Sum Sq. Dev & 175.6249 & 116.0553 & 1.9263 & 4564.694 & 5.8500 & 3.8715 \\
\hline
\end{tabular}

Source: Software E-Views 10 helps to calculate these figures.

Mean is mostly used as a tool to measure the average. From the above table, the mean value of GFCF has been 16.2091 for the last 43 years, it shows that the flow of capital formation is sensible in Pakistan as this value shows the gross fixed capital formation is high in Pakistan for the last 43 years. The Standard Deviation method is used to measure variations in the data. This study represents the Standard Deviation value of GFCF as 1.6622, which shows a moderate level of 
fluctuations in GFCF over a period. Now, the mean value of HE is 0.7034 , which means the level of health expenditure in Pakistan is quite high. While the health expenditures of Pakistan have a Standard Deviation value of 0.2141 , it depicts that health expenditures show a little bit of variation from their average value. The average value of TGE is 57.1016, which means the level of generation of electricity is a bit high in Pakistan. While the value of the Standard Deviation of the total generation of electricity is 10.4251 , it describes that the total generation of electricity in Pakistan shows a high level of divergence from its average value. LF in Pakistan shows the average value is 50940668, it depicts a high level of LF in Pakistan. The Standard Deviation value of the labor force is 11801104 , which present that the labor force shows a quite high level of variation from its mean value. The mean value for GEE is 2.4329 as this value shows the government expenditures on education is low in Pakistan for the last 43 years. The Standard Deviation value of GEE is 0.3036 and it represents that GEE has a significant variation from its mean value.

In the statistics, the central value of the observations or the middling value of two central observations is known as the median. In the above explain table the values of the median of GDP, GFCF, HE, TGE, LF, and GEE are 4.846, 16.8371, 0.7300, 62.6726, 53655064 are 2.4918 respectively. The highest value in the set of observations is called maximum. GDP, GFCF, HE, TGE, LF, and GEE have maximum values as 10.2157, 19.2354, 1.2500, 71.8260, 69957925, and 3.0223 respectively. The minimum is known as the lowest value in the set of observations. Minimum values of GDP, GFCF, HE, TGE, LF, and GEE are 1.0143, 12.5206, 0.2300, 37.9959, 31130954 and 1.8378 respectively.

Distribution can be distributed into two categories such as skewed or asymmetric distribution and symmetric distribution. If the value of skewness is superior to zero, then the worth of distribution is positively skewed and it has a long right tail. The value of the distribution will be negative if the value of skewness is less than zero and it has a long left tail. If the value of skewness is precisely equal to zero, then the distribution will be symmetric and has long equal tails. In this paper the values of skewness of variables GFCF, TGE, LF, and GEE are less than zero, therefore these variables are negatively skewed. GDP and HE have values of skewness greater than zero; therefore, these variables are positively skewed. To measure the degree of flatness of a unimodal frequency curve a statistical tool is used which is known as Kurtosis.

If $\sim 2>3 \rightarrow$ the curve is highly peaked, and it is leptokurtic. If $\sim 2<3 \rightarrow$ the curve is flat-topped, and it is platykurtic.

If $\sim 2=3 \rightarrow$ the curve is normally peaked, and it is mesokurtic.

In this study, the value of Kurtosis of $\mathrm{HE}$ is 3.4432, which means health expenditures are leptokurtic. While the values of Kurtosis of GDP, GFCF, TGE, LF, and GEE are 2.7581, 2.2946, 1.8873, and 2.1715 it means they are platykurtic. J.B Test indicates that whether the variables are normally distributed or not. From the table, all the variables are normally distributed by looking at the values of their probabilities. The following table is prepared to check the stationary of data with the help of software.

Table 2: Approximations of ADF

\begin{tabular}{l|llll|l}
\hline \multicolumn{3}{|l}{ At Level } & At 1 ${ }^{\text {st }}$ & \\
\hline Variables & I & I\&T & I & I\&T & Results
\end{tabular}

\begin{tabular}{|c|c|c|c|c|c|}
\hline$\overline{\text { GDP }}$ & $-4.1715^{*}$ & $-4.6720^{*}$ & $-10.3730^{*}$ & $-10.2413 *$ & $\mathrm{I}(0)$ \\
\hline GFCF & -2.0940 & -3.5952 & $-6.1001 *$ & $-5.9523 *$ & $\mathrm{I}(1)$ \\
\hline
\end{tabular}




$\begin{array}{cccccc}\text { HE } & -2.1413 & -2.7737 & -6.8186^{*} & -6.7154^{*} & \text { I (1) } \\ \text { TGE } & -1.1090 & -0.8833 & -10.1289^{*} & -10.0708^{*} & \text { I (1) } \\ \text { LF } & -1.2845 & -1.3603 & -5.9180^{*} & -5.9365^{*} & \text { I (1) } \\ \text { GEE } & -3.1667 & -3.2773 & -6.5742^{*} & -6.4748^{*} & \text { I (1) }\end{array}$

Source: Deliberate and carry out with the help of E-views 10 (Qualitative Software).

This table is prepared with the help of E-Views Software 10 to check whether the variables, choose for this paper are stationary or not. The stationary of the data means that for a period, there are no changes in mean, variance, and covariance of the time series data use in the study. To check the stationary level ADF (Augmented Dickey-Fuller) test is applied. The stationery levels of variables are checked to avoid weakening the regression of the time series data used in this paper. It can be observed from the above table that GDP is stationary at level, i.e. I (0), and GDP has zero sorts of integration. GFCF is stationary at $1^{\text {st }}$ difference, i.e. I (1), and it has the order of integration 1.

Table 3: Results of Bound Test for Cointegration

\begin{tabular}{lccc}
\hline Equation & F-Statistics & $\begin{array}{c}\text { Upper Bound } \\
\text { (Critical Value) }\end{array}$ & Results \\
\hline GDP/GFCF, HE, & 5.1020 & 3.28 & Co-integration subsist \\
TGE, LF, GEE & & \\
\hline
\end{tabular}

\section{Source: Author's Calculation (E-VIEWS 10)}

In the above table, the Bound Test is applied. As can be seen in above table 4, the calculated value of the $\mathrm{F}$ - statistic is 5.1020 which is greater than the Upper Bound value or critical value which is 3.28. The superiority of the F - statistic value illustrates that there exists a long-run cointegration in this approach. The software E-views 10 is used to form this table. The correlation coefficient describes the level of association between two variables. A correlation mold illustrates each probable correlation coefficient with a set of variables. The correlation matrix of the variables of the sculpt is given as:

Table 5: Correlation Matrix

\begin{tabular}{|c|c|c|c|c|c|c|}
\hline & GDP & GFCF & HE & TGE & $\mathbf{L F}$ & GEE \\
\hline$\overline{\text { GDP }}$ & 1.00 & & & & & \\
\hline GFCF & 0.27 & 1.00 & & & & \\
\hline HE & 0.28 & 0.51 & 1.00 & & & \\
\hline TGE & -0.53 & -0.45 & -0.56 & 1.00 & & \\
\hline LF & 0.29 & -0.36 & -0.14 & -0.22 & 1.00 & \\
\hline
\end{tabular}




$\begin{array}{lllllll}\text { GEE } & -0.29 & 0.04 & 0.25 & 0.34 & -0.11 & 1.00\end{array}$

\section{Source: E-Views 10}

The above table represents that GDP has a direct or positive association with GFCF, HE, and LF of order $0.27,0.28$, and 0.29 respectively. While GDP has an indirect or inverse association with TGE and GEE of order -0.53 and -0.29 respectively. Similarly, GFCF has a positive link with HE and LF while it has a negative link with TGE and GEE.

Table 6: Short Run Estimates of Model

\begin{tabular}{|c|c|c|c|c|}
\hline Variables & Coefficient & St. Errol & t-statistics & Probability \\
\hline$\overline{\mathrm{D}(\mathrm{GDP}(-1))}$ & -0.2797 & 0.1778 & -5.4696 & 0.0000 \\
\hline $\mathrm{D}(\operatorname{GFCF}(-1))$ & 0.1348 & 0.2870 & 0.4698 & 0.6414 \\
\hline $\mathrm{D}(\mathrm{HE})$ & 1.8639 & 2.1638 & 0.8614 & 0.3950 \\
\hline $\mathrm{D}(\mathrm{TGE}))$ & -0.0424 & 0.0511 & -0.8302 & 0.4122 \\
\hline $\mathrm{D}(\mathrm{LF}))$ & 0.4908 & 0.3338 & 1.4730 & 0.1499 \\
\hline $\mathrm{D}(\mathrm{GEE}))$ & -1.5496 & 1.3833 & -1.1201 & 0.2705 \\
\hline CointEq (-1) & -0.3862 & 0.1495 & -0.0738 & 0.0000 \\
\hline \multicolumn{5}{|c|}{ Cointeq=GDP-(-0.1386*GFCF+1.9161*HE-0.0437*TGE+0.0000*LF-1.5929*GEE+5.1602) } \\
\hline R-Squared & 0.4091 & \multicolumn{2}{|c|}{ AIC } & 4.1204 \\
\hline Adjusted R-Squared & 0.2874 & \multicolumn{2}{|c|}{ SBC } & 4.4514 \\
\hline F-statistics & 3.3632 & \multicolumn{2}{|c|}{ HQC } & 4.2417 \\
\hline Prob.(F-statistics) & 0.0078 & \multicolumn{2}{|c|}{ Durbin-Watson Stat } & 1.9953 \\
\hline
\end{tabular}

Source: E-Views 10

The above table shows the short-run estimation of variables with the counter equation. The computed values of R-Squared and Adjusted R-Squared are 0.40 and 0.28 respectively. This means there is a $40 \%$ and $28 \%$ variation in GDP through independent variables like GFCF, HE, TGE, LF, and GEE. The value of the Durbin-Watson Test is 1.99 which means there is no autocorrelation between dependent and independent variables. Divergence of the estimated value from the original value is known as the Cointeq value. The counter has the value -0.3862 which is quite significant as it can be seen from the value of its probability of 0.0000 . Mutual boundaries of negative signs and significance have been fulfilled here. Amendments to restore the velocity of long-run equilibrium are known as Counter. The steady long-run link between variables can be established by looking at the extremely momentous value of Cointeq. The results of the table show that the disequilibria have been converted into equilibrium as the value of the velocity of 
the amendment is very high.

Table 7: Long Run Estimates of Model

\begin{tabular}{lcccc}
\hline Variables & Coefficient & St. Error & t-statistics & Probability \\
\hline GFCF & 0.1386 & 0.2849 & 0.4865 & 0.6297 \\
HE & 1.9161 & 2.1984 & 0.8715 & 0.3895 \\
TGE & -0.0436 & 0.0537 & -0.8128 & 0.4219 \\
LF & 0.5048 & 0.3198 & 1.5808 & 0.1232 \\
GEE & -1.5929 & 1.3872 & -1.1842 & 0.2589 \\
C & 5.1602 & 7.3286 & 0.7041 & 0.4862 \\
\hline
\end{tabular}

\section{Source: Author's Calculation (E-VIEWS 10)}

This table describes the long-run estimation of the model. In the table, the value of the coefficient of GFCF is 0.1386 and it is positive. The value of GFCF describes that the $1 \%$ rise in GFCF will increase the GDP by $13 \%$. The direct relationship between GDP and GFCF shows that the Government should invest more in the field of gross fixed capital formation by installing new and developed machinery and by developing the production system. Similarly, the independent variables like $\mathrm{HE}$ and LF have a positive or direct relationship with the dependent variable GDP. It means a $1 \%$ increase in HE will bring a rise of $191 \%$ in the GDP and the $1 \%$ rise in LF will increase the GDP by $50 \%$. Therefore, the government of Pakistan should focus on the abovementioned sectors for the economic growth of Pakistan. These positively related variables are statistically significant.

On the other hand, the described variables of this study like TGE and GEE have a negative or indirect relationship with the GDP. The negative results show that a $1 \%$ increase in TGE will decrease the GDP by $40 \%$. For the generation of electricity, the government needs to be developed and costly machinery, equipment, and fuels for which the government must spend a huge amount of money, which in turn will put a great burden on the budget of the country. Similarly, government expenditures on education have an inverse connection with the GDP in this study, it describes that despite investing more in the new educational projects the government must try to develop the existing education system. These negatively related variables are statistically insignificant.

Table 8: Diagnostic Test for Model

\begin{tabular}{lcc} 
Name of Test & F-statistic & Probability \\
\hline & & \\
\hline Breusch-Godfrey Co-relation LM Test & 0.1184 & 0.7335 \\
Heteroskedasticity Test & 0.5124 & 0.8383 \\
\hline
\end{tabular}

Source: E-Views 10.

Many techniques are used to measure correlation, heteroscedasticity, and misspecification in any approach. The above table explains that the correlation and heteroskedasticity are not present in this approach and the model is correctly specified because their probability values are greater than 0.05 .

The following graph depicts that this sculpt is significant at the level of 5\%. The red lines in the graph demonstrate the upper and lower boundaries. The cumulative sum of recursive residuals (CUSUM) is plotted below in the graph, which shows a 5 percent significance level. In the test, upper and lower critical boundaries exist, such as the straight lines in the figure. 


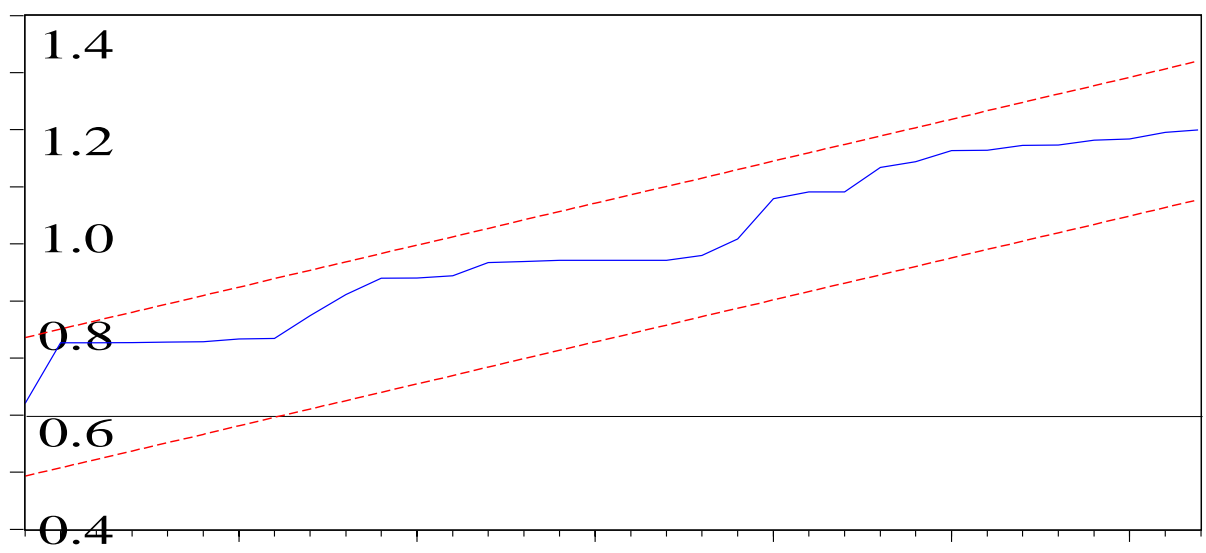

0.2

O.O

$-0.2$

$-0.4$

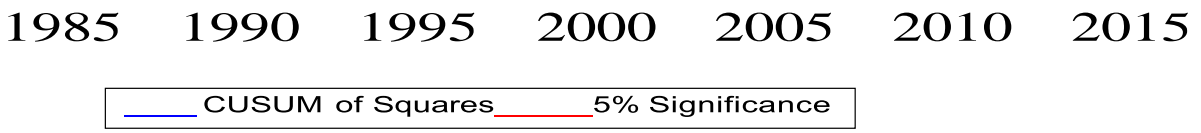

The Cumulative Sum of Recursive Residual of Squares (CUSUM) is plotted in the following graph, with a 5\% level of significance.

Figure 2: Plot of Cumulative Sum of Square Recursive Residual Test 20

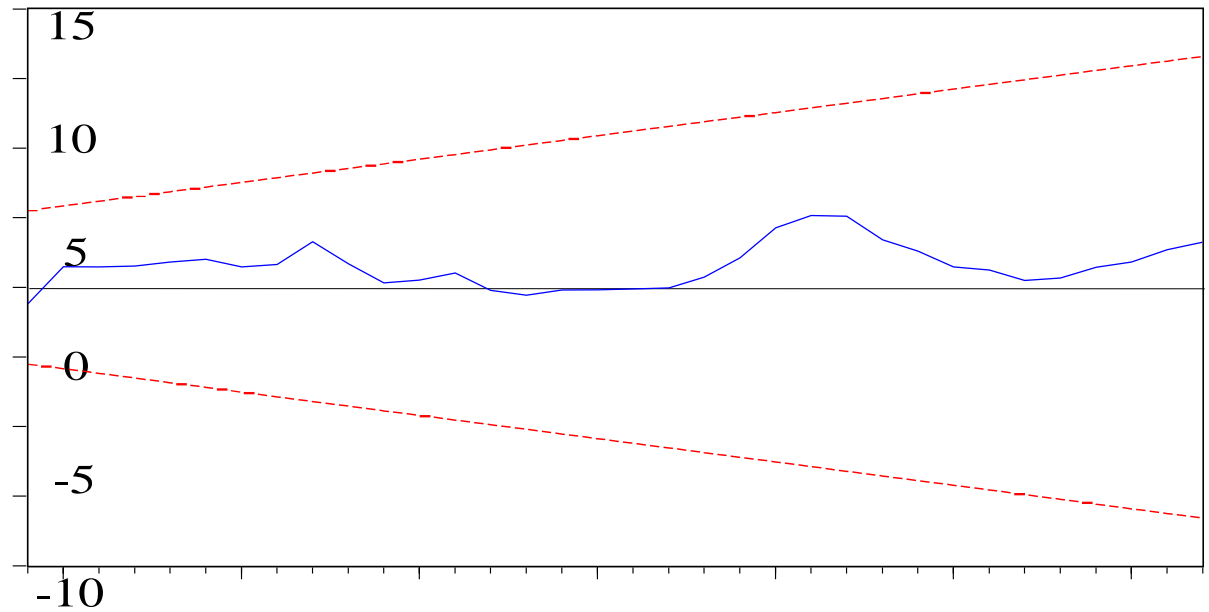

$-15$ 


\section{CUSUM _ $5 \%$ Significance \\ $-20$ \\ $\begin{array}{lllllll}1985 & 1990 & 1995 & 2000 & 2005 & 2010 & 2015\end{array}$}

\section{Conclusion and Recommendations}

The outcomes of this study show that these variables represented as the infrastructure of Pakistan put mixed impacts on the GDP of Pakistan. A positive association is witnessed between gross domestic product and gross fixed capital formation, health expenditure, and labor force of Pakistan. It means an increase in GFCF, HE, and LF of the country will automatically enhance the economic growth of Pakistan. This is the reason the government should plant the new machinery for a production system, make more investment in the health sector, and improving labor skills. Similarly, GDP shows an inverse relation with TGE and GEE in the analysis of this study. It describes that a minor increase in TGE and GEE will reduce the growth of the economy of Pakistan. These two factors are important for any economy, but in the case of Pakistan; the investment in these two sectors TGE and GEE will affect the economy of Pakistan negatively.

Any economy desires to gain a higher level of economic growth. Generally, the high rate of GDP represents the flourished economy. To increase the economic growth of Pakistan through the development of the pharmaceutical industry of Pakistan, the following actions are recommended:

i. Health is one of the important factors of Human Capital. To increase the productivity of labor, better health is necessary. But, unfortunately, the government of Pakistan is focusing less on the improvement of the health sector of Pakistan or the provision of better and basic health facilities to the public. The government of Pakistan should spend to construct new hospitals and clinics; subsidies should be given to the drug-producing companies.

ii. Labor is an effective and efficient part of any economy because it is one of the factors of production. This study witnesses a positive link with the gross domestic product of Pakistan, this is the reason the government of Pakistan should work on the development of the labor force. For the development of the labor force, the government should organize training sessions, workshops, institutions for technical and vocational education, and many other projects.

\section{References}

Afzal, H. (2012). Impact of Electricity Crisis and Interest Rate on Textile Sector of Pakistan. Academy of Contemporary Research Journal, 1(1), pp. 32-33.

Aoyagi, K., Sawada, Y., \& Shoji, M. (2014). Does infrastructure facilitate social capital accumulation? Evidence from natural and artefactual field experiments in a developing country. JICA-RI Working Papers, (65).

Boadi, I., Dana, L. P., Mertens, G., \& Mensah, L. (2017). SMEs' financing and banks' profitability: a "good date" for banks in Ghana?. Journal of African Business, 18(2), 257277.

Bougheas, S., Demetriades, P. O., and Morgenroth, E. L. (2003). International aspects of public infrastructure investment. Canadian Journal of Economics/Revue Canadienne' économique, 36(4), 884-910.

Canning, D., and Pedroni, P. (2004). The effect of infrastructure on long-run economic growth. Harvard University, 1-30.

Canning, D., and Pedroni, P. (2004). The effect of infrastructure on long-run economic growth. Harvard University, 1-30. 
Dissou, Y. and Didic, S (2011). Public Infrastructure and Economic Growth. Working Paper, Department of Economics. The University of Ottawa.

Dissou, Y. and Didic, S (2011). Public Infrastructure and Economic Growth. Working Paper, Department of Economics. The University of Ottawa.

Estache et al (2009). Impact of Infrastructure Spending in Mali: A CGE Modeling Approach. Universite Libre de Bruxelles, Ecares, ECARES Working Papers 2009 - 009.

Mahmood, T., Hafeez-ur-Rehman, and S. A. Rauf, (2008). Evaluation of Macro-Economic Policies of Pakistan (1950-2008). Journal of Political Studies, 14, 57-75.

between leader emotional intelligence, team culture and team performance of healthcare institutions in Pakistan/Samia Jamshed (Doctoral dissertation, University of Malaya).

Tanveer, A., and Manan, N.(2016). Impact of Infrastructure on Economic Growth of Pakistan. Journal of Economic Research, 2(1).1-12.

World Economic Forum, (2010). Global Competitiveness Report. Geneva, Switzerland.

Yilmaz, S., Haynes, K., and Dinc, M. (2002). Telecommunication and Regional Development: Evidence from the U.S. States. Economic Development Quarterly, 16(3), 211-228. Rao, P. S., and Srinivasu, B. (2013). Infrastructure Development and Economic growth: Prospects and Perspective. Journal of Business Management \& Social Sciences Research, 2(1), 81-91.

Rygzynov, T. S., \& Tsydypov, V. E. (2019, August). The role of international infrastructure projects in the sustainable social and economic development of the border areas (the case of Russia and Mongolia).

In IOP Conference Series: Earth and Environmental Science (Vol. 320, No. 1, p. 012012). IOP Publishing.

Samia, J. (2018). The relationship between leader emotional intelligence, team culture and team performance of healthcare institutions in Pakistan/Samia Jamshed (Doctoral dissertation, University of Malaya).

Tanveer, A., and Manan, N.(2016). Impact of Infrastructure on Economic Growth of Pakistan. Journal of Economic Research, 2(1).1-12.

World Economic Forum, (2010). Global Competitiveness Report. Geneva, Switzerland.

Yilmaz, S., Haynes, K., and Dinc, M. (2002). Telecommunication and Regional Development: Evidence from the U.S. States. Economic Development Quarterly, 16(3), 211-228. 